\title{
Overheating mitigation in buildings: a computational exploration of the potential of phase change materials
}

\author{
Nedim Hodzic ${ }^{1}$, Ulrich Pont ${ }^{1,{ }^{*}}$, Fahrang Tahmasebi ${ }^{2}$, and Ardeshir Mahdavi ${ }^{1}$ \\ ${ }^{1}$ Department of Building Physics and Building Ecology, TU Wien, Vienna, Austria \\ ${ }^{2}$ Institute for Environmental Design and Engineering, University College, London, UK
}

\begin{abstract}
Phase change materials (PCMs) can store and release thermal energy. The energy is stored when the material goes through a solid-toliquid phase change, and released in the reverse process. Such materials can contribute to the mitigation of overheating in buildings, if their melting and solidification temperatures are in a suitable range. The present contribution entails a computational examination of this potential as relevant to overheating mitigation in typical residential units in the Central European context of Vienna, Austria. Thereby, multiple variations of PCM application (size, thickness, location, and application thickness) under different contextual settings (fenestration and insulation, boundary conditions in terms of weather) were simulated and comparatively evaluated. Results indicate that certain PCM application configurations can significantly influence indoor thermal condition. For instance, PCM elements with larger surface areas displayed a more pronounced effect as compared to bulkier elements with smaller surface areas. Likewise, ceilingintegrated PCM application was found to be more effective that those involving other room surfaces. The results also highlight the importance of rooms ventilation regime if the PCM application potential toward overheating mitigation is to be effectively harvested.
\end{abstract}

\section{Introduction}

The present contribution focuses [1] on application potential of Phase Change Materials (PCMs) as mitigation measure against overheating in Vienna, Austria. The key research question was if a PCM incorporation in a typical Viennese building provides enough latent heat storage to increase thermal comfort and energy efficiency (by rendering active cooling unnecessary). To pursue this question, a simulation-based approach was selected. Thereby, variations of parameters of the Phase Change Materials such as application form and panel surface area were examined, as well as boundary condition parameters, such as night-time ventilation. Simulation models of two spaces in a typical Viennese Gründerzeit building stock (characterized by massive wall constructions and wooden truss slabs) were generated.

PCMs in buildings are one form of Thermal Energy Storage (TES) and can be used to enhance passive cooling potential. Thermal energy storage is achievable via sensible, latent, or thermochemical heat storage. PCMs utilize phase change enthalpy, thus they are 
considered to be latent heat storage. During the phase transition, thermal energy is stored in the material within a narrow temperature span. The first scientific approach onto the application of PCMs in buildings can be dated back to 1947, where PCMs based on Glauber slats were used as passive solar heating system [2]. However, there are only few further scientific publications regarding the use of PCMs in buildings until the year 2003 (Soares et al. [3] name just 2 papers that have been published before 2003). In recent years the idea of using PCMs in buildings gained momentum, also resulting in increased published research efforts by different researchers [3]. Typically, three different types of PCM-materials are distinguished: organic compounds, inorganic compounds, and eutectics [4]. Another categorization of PCMs is the distinction in PCMs with micro and macro encapsulation. Micro-encapsulation means the encapsulation of the PCM-material in very small containments and amongst other materials. Application examples of such micro encapsulations include gypsum wallboards, PCM-containing plaster products, or integrated pads in furniture surfaces. While micro encapsulation offers convenient advantages, such as easy application and integration in existing rooms, its performance is limited due to the rather small extent of material used. Macro encapsulation involves the use of large volumes of PCM materials (e.g., in panels of different form). However, their larger thickness may lead to incomplete phase-changing processes or sub-cooling phenomena.

The present contributions focuses on Macro-encapsulation PCMs. Regarding the selection of the right PCM-product for a specific task within a building, the following criteria have been suggested: PCMs used in buildings should have a large latent heat capacity and a high thermal conductivity. PCMs in buildings are required to have their phase change within regular thermal comfort ranges of indoor spaces (that is $18^{\circ} \mathrm{C}$ to $30^{\circ} \mathrm{C}$ ) [5]. Khudair and Farid [6] suggest that the optimal diurnal heat storage occurs with a melting temperature of 1 to 3 Kelvin above the average room temperature. Figure 1 illustrates temperature/melting ranges of different PCM materials relevant to typical room temperatures. Building-related potential of PCMs has been explored in a number of previous research efforts (see, for example, Khuair and Farid [6], Lee et al. [7], Kenisarin et al. [8], Tyagi et al. [9], Sharma et al. [10], Skovajsa et al. [11], Menon [12]).

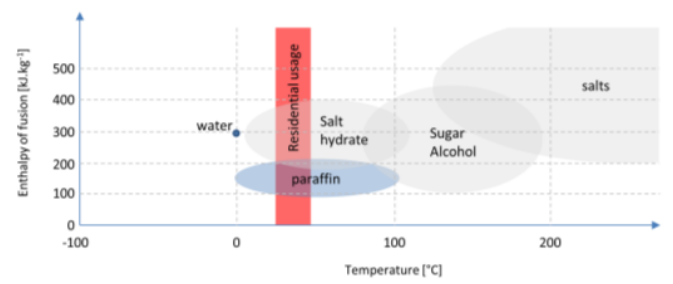

Fig. 1 Temperature /Melting ranges of different PCMs (based on [11][12])

\section{Methodology}

\subsection{Case study rooms}

The two case study rooms used in this study are situated in a typical Viennese Gründerzeit building. Both rooms (denoted as TR1 and TR2) have their cardinal orientation towards southeast and feature two windows. TR1 is situated in the third floor of the building and features two regular windows, while TR2 is situated in the attic space and has two skylights. Thermal properties of the constituting building elements are based on the OIB Guideline 6 [13]. Table 1 includes key information on both rooms. Figures 2 and 3 provide plan and 3-D views of the rooms and their location in the respective buildings. 
Table 1. Information on the two case study rooms TR1 and TR2

\begin{tabular}{|c|c|c|c|}
\hline Room & Surface \& Abbreviation & Area $\left[\mathrm{m}^{2}\right]$ & U-value $\left[\mathrm{W} \cdot \mathrm{m}^{-2} . \mathrm{K}^{-1}\right]$ \\
\hline \multirow{4}{*}{ TR1 } & Ceiling TR1_C & 25.97 & 0.75 \\
\cline { 2 - 4 } & Floor TR1_F & 25.97 & 0.75 \\
\cline { 2 - 4 } & Outside wall TR1_OW & 12.74 & 1.55 \\
\cline { 2 - 4 } & Partition wall Southwest TR1_SW & 21.28 & 1.55 \\
\cline { 2 - 4 } & & 14.76 & 1.55 \\
\cline { 2 - 4 } & Partition wall Northwest TR1_NW & 21.34 & 1.55 \\
\cline { 2 - 4 } & Partition wall Northeast TR1_NE & 3.61 & 2.50 \\
\cline { 2 - 4 } & Windows (Southeast) & 17.79 & 1.30 \\
\cline { 2 - 4 } & Roof TR2_R & 4.22 & 1.30 \\
\cline { 2 - 4 } & Tilted roof TR2_RT & 22.32 & 0.75 \\
\cline { 2 - 4 } & Floor TR2_F & 14.18 & 1.55 \\
\cline { 2 - 4 } & Adjacent wall TR2_AW & 5.68 & 1.55 \\
\cline { 2 - 4 } & Partition wall Southeast TR2_SE & 14.12 & 1.55 \\
\cline { 2 - 4 } & Partition wall Northeast TR2_NE & 6.42 & 1.55 \\
\cline { 2 - 4 } & Outside wall TR2_OW & & 2.50 \\
\cline { 2 - 4 } & Windows (sloped, southeast) & & \\
\hline
\end{tabular}

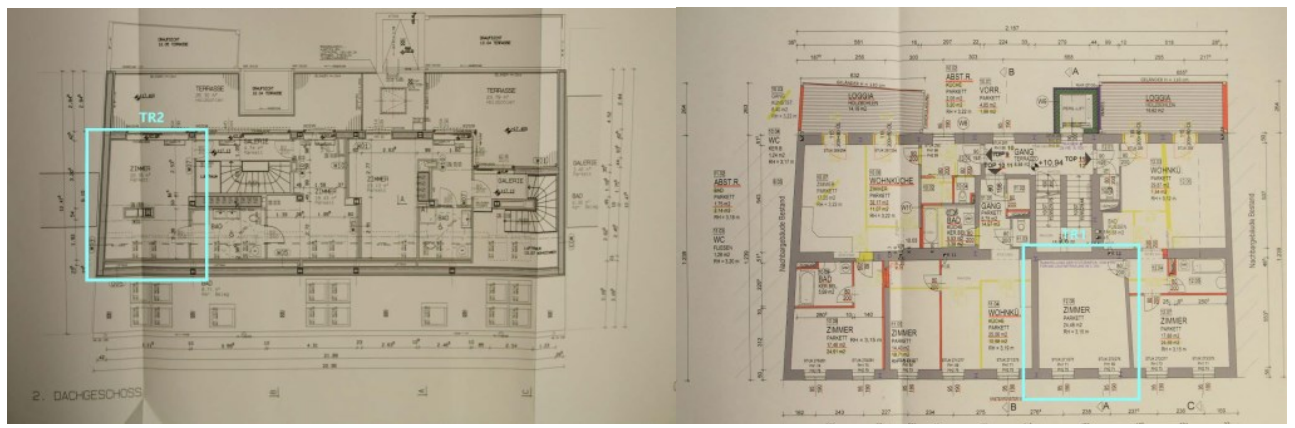

Fig. 2 Plans of TR1 (right) and TR2 (left)

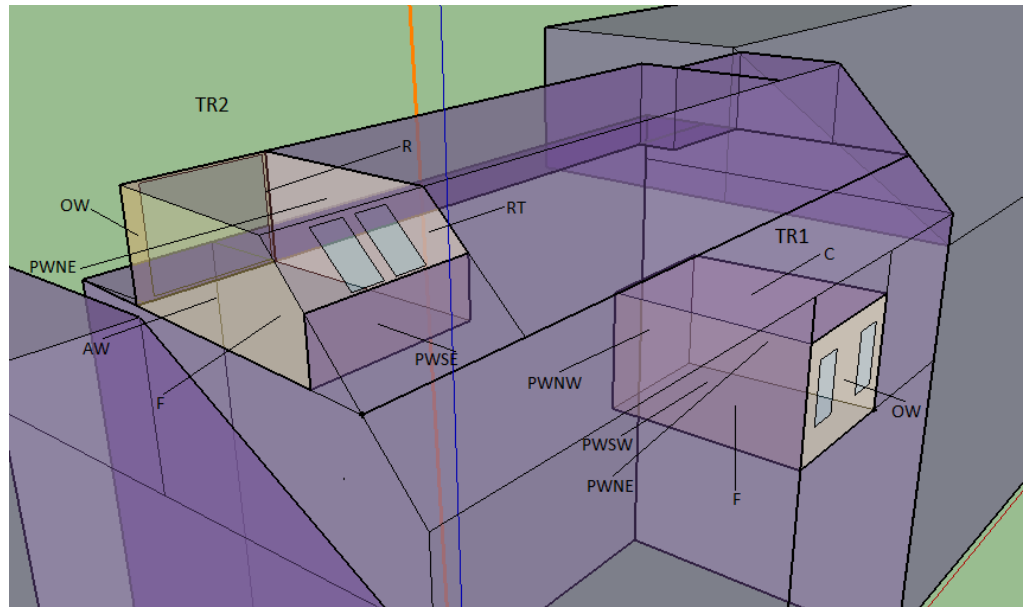

Fig. 3 3-D view of TR1 and TR2 


\subsection{Phase Change Material and Integration in test rooms}

The chosen PCM is a (macro-encapsulation) product of the company Entropy Solutions LLC (Plymouth, Minnesota), namely PureTemp 25 [14] (see Table 2 for key technical information and Figure 4 for melting/solidification characteristics). It is of organic origin, has been extensively tested, and is suggested to accommodate 10.000 diurnal cycles without significant change of performance or characteristics. This corresponds to a lifecycle of 27 years (daily usage scenario) or 50 years (summer time usage scenario). Table 2 denotes the characteristics of the material. The main applications scenario in the present study involves mounting of panels to the ceilings of the test rooms. Nonetheless, the effect of placing the panels on other surfaces (especially walls) was examined as well. Three layer thicknesses of the PCM panels were evaluated $(3,5$, and $7 \mathrm{~cm})$.

Table 2. Technical information on the selected PCM

\begin{tabular}{lr|lr}
\multicolumn{1}{c|}{ Aspect } & \multicolumn{1}{|c}{ Aspect } \\
\hline Appearance & Clear liquid, waxy solid & Density (liquid) & $0.86 \mathrm{~g} \cdot \mathrm{ml}^{-1}$ \\
Melting point & $25^{\circ} \mathrm{C}$ & Density (solid) & $0.95 \mathrm{~g} \cdot \mathrm{ml}^{-1}$ \\
Heat storage capacity & $187 \mathrm{~J} \cdot \mathrm{g}^{-1}$ & Specific heat (liquid) & $2.29 \mathrm{~J} \cdot \mathrm{g}^{-1} \cdot \mathrm{K}^{-1}$ \\
Thermal cond. (liquid) & $0.15 \mathrm{~W} \cdot \mathrm{m}^{-1} \cdot \mathrm{K}^{-1}$ & Specific heat (solid) & $1.99 \mathrm{~J} \cdot \mathrm{g}^{-1} \cdot \mathrm{K}^{-1}$ \\
Thermal cond. (solid) & $0.25 \mathrm{~W} \cdot \mathrm{m}^{-1} \cdot \mathrm{K}^{-1}$ & &
\end{tabular}

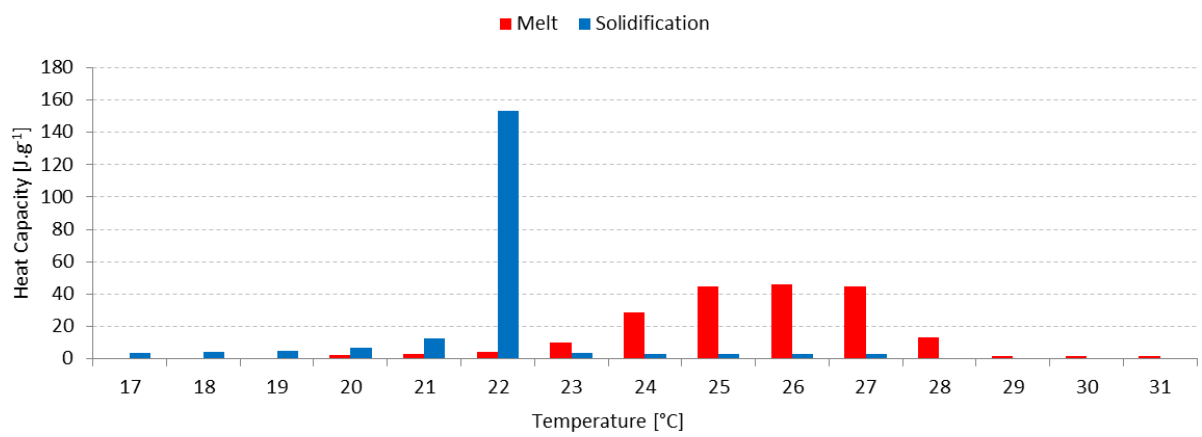

Fig. 4 Melting / Solidification characteristics of PureTemp25

\subsection{Simulation tool, simulation scenarios, settings $\&$ boundary conditions}

The effect of the applied PCM-panels was studied using EnergyPlus [15], which has been suggested as a suitable tool for the topic at hand [16][17]. Climate data was used based on measurement results obtained from our Department's weather station in Vienna. Regarding internal conditions, applicable Austrian Standards data was used [18].

Several application scenarios were simulated for both test rooms. Thereby, the application of PCM panels and the ventilation regimes were varied. Moreover, as base-line scenarios, both rooms were simulated without PCM application but under different ventilation scenarios. Toward this end, both tilted and fully open window positions were considered, implying air change rates between 0.5 and $4.0 \mathrm{~h}^{-1}$. Moreover, a differentiation between Day time ventilation and Night time ventilation was considered. Table 3 illustrates some the scenarios evaluated. The key to the scenario labels in this Table can be decoded as follows: Test room (TR1 or TR2)_PCM Position and Thickness (if applicable)_Daytime Ventilation_Night-time Ventilation. 
Table 3. Some of the evaluated Scenarios

\begin{tabular}{|c|c|c|}
\hline Room & Scenario & Description \\
\hline \multirow{4}{*}{ TR1 } & TR1_DV0.5_NV2 & No PCM application, day-time Ventilation DV $0.5 \mathrm{~h}^{-1}$, \\
night-time Ventilation NV $2 \mathrm{~h}^{-1}$
\end{tabular}

\section{Results}

Figure 5 illustrates the resulting TR1 temperatures for different scenarios for TR1 as cumulative graphs. The information entailed in this Figure reveals both the PCM application influence and the importance of ventilation rates. PCM application as such cannot replace proper ventilation, especially during night-time. The performance of those scenarios with PCM, where ventilation is drastically reduced, can be worse than properlyventilated cases without PCM. Table 4 encapsulates the main results for both TR1 and TR2.

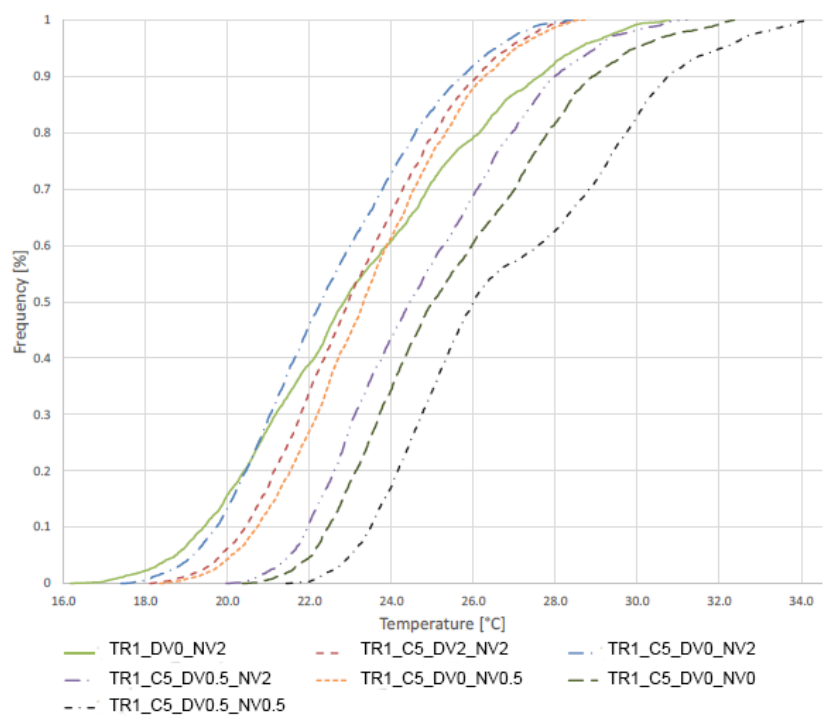

Fig. 5 Cumulative temperature distribution graph for the scenarios of TR1. 
Table 4. Simulation results for selected scenarios

\begin{tabular}{|c|c|c|c|c|c|c|c|c|}
\hline TR1 & 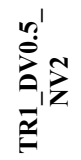 & 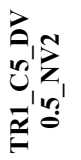 & 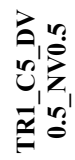 & 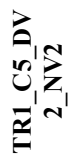 & 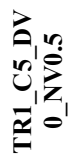 & 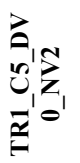 & 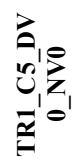 & 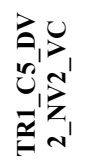 \\
\hline Temperature $>27^{\circ} \mathrm{C}[\mathrm{h}]$ & 482 & 154 & 719 & 105 & 1107 & 192 & 1575 & 84 \\
\hline Temperature $>27^{\circ} \mathrm{C}[\%]$ & 13.13 & 4.19 & 19.58 & 2.86 & 30.15 & 5.23 & 42.89 & 2.29 \\
\hline Mean temperature $\left[{ }^{\circ} \mathrm{C}\right]$ & 23.21 & 23.11 & 24.77 & 22.51 & 25.47 & 23.42 & 26.84 & 22.54 \\
\hline Max temperature $\left[{ }^{\circ} \mathrm{C}\right]$ & 30.79 & 28.54 & 31.20 & 28.46 & 32.37 & 28.71 & 34.22 & 28.22 \\
\hline TR2 & 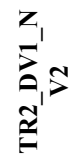 & 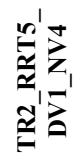 & 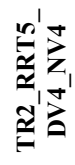 & 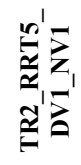 & 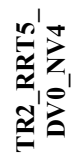 & 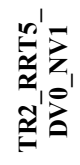 & 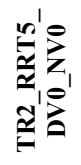 & 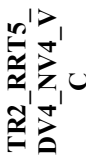 \\
\hline Temperature $>27^{\circ} \mathrm{C}[\mathrm{h}]$ & 1222 & 871 & 635 & 1368 & 1008 & 1684 & 2060 & 637 \\
\hline Temperature $>27^{\circ} \mathrm{C}[\%]$ & 33.28 & 23.72 & 17.29 & 37.25 & 27.45 & 45.86 & 56.10 & 17.35 \\
\hline Mean temperature $\left[{ }^{\circ} \mathrm{C}\right]$ & 24.98 & 24.64 & 23.66 & 26.49 & 25.20 & 27.48 & 29.10 & 23.75 \\
\hline Max temperature $\left[{ }^{\circ} \mathrm{C}\right]$ & 36.93 & 35.95 & 33.90 & 38.14 & 37.36 & 39.94 & 41.47 & 33.90 \\
\hline
\end{tabular}

These results suggest that the application of PCMs can significantly lower both indoor temperature peaks (maximum temperatures during summer seasons) and average indoor air temperatures. Furthermore, the number of overheating hours (hours with an indoor air temperature of higher than $27^{\circ} \mathrm{C}$ ) can be reduced during summer season, if PCM deployment is combined with proper ventilation regimes.

Increasing the thickness of the PCMs can further reduce overheating hours. However, the effect involves a diminishing return, as it weakens the thicker the panel becomes. Table 5 shows the impact of 3, 5, and $7 \mathrm{~cm}$ of ceiling-mounted PCMs (based on scenario TR1 _C5_DV0.5_NV2).

Table 5. Impact of 3, 5, and $7 \mathrm{~cm}$ of PCM in TR1_C(3,5,7)_DV0.5_NV2

\begin{tabular}{|c|c|c|c|}
\hline & & & \\
\hline TR1_C(3,5,7)_DV0.5_NV2 & & & \\
& 218 & 154 & 136 \\
\hline Temperature $>27^{\circ} \mathrm{C}[\mathrm{h}]$ & 5.94 & 4.19 & 3.70 \\
\hline Temperature $>27^{\circ} \mathrm{C}[\%]$ & 23.19 & 23.11 & 23.07 \\
\hline Mean temperature $\left[{ }^{\circ} \mathrm{C}\right]$ & 28.99 & 28.54 & 28.40 \\
\hline Max temperature $\left[{ }^{\circ} \mathrm{C}\right]$ & & & \\
\hline
\end{tabular}

\section{Conclusion, limitations of the study, and future research}

The present contribution utilized a simulation-based assessment of the impact of PCM application in typical rooms in the building stock in Vienna, Austria. Thereby, the application of PCMs was shown to be effectual in view of reducing peak and average temperatures in the examined rooms, if combined with appropriate ventilation regimes. As such, deployment of PCM can enhance, but not replace, the utilization of smart ventilationbased cooling strategies. Details of the entire set of conducted simulations [1] could not be covered within the framework of the present paper. Nonetheless, it would be appropriated 
to briefly mention at least two additional findings of the study: $i$ ) The application of PCMs on the ceiling appears to represent most efficient positioning option; ii) Large-area panels appear to be more effective than thicker ones.

Needless to say, a purely simulation-based study has shortcomings, including - most importantly - the absence of measurement-based validation. Thus, empirical studies must be performed in the course of future research efforts. Likewise, a larger set of case study buildings must be considered, addressing different building types, construction methods, use patterns, urban context, and microclimatic boundary conditions.

\section{References}

1. N. Hodzic: "Phase Change Materials as a thermal Retrofit Option for Buildings in Vienna"; Master Thesis, Department of Building Physics and Building Ecology, TU Wien, Vienna, Austria 2018.

2. M. Telkes: "Trombe wall with phase change storage material" In: Proceedings of the 2nd national passive solar conference, 1978, Philadelphia.

3. N. Soares, J.J. Costa, A.R. Gaspar, P. Santos, 2012. "Review of passive PCM latent heat thermal energy storage systems towards buildings' energy efficiency." Energy and Buildings 59 (2013), pp. 82-103. DOI: 10.1016/j.enbuild.2012.12.042.

4. W.C. Choi, B.-S. Khil, Y.-S. Chae, Q.-B. Liang, H.-D. Yun, "Feasibility of Using Phase Change Materials to Control the Head of Hydration in Massive Concrete Structures." The Scientific World Journal, Volume 2014, Article ID 781393, http://dx.doi.org/10.1155/2014/781393.

5. D. Zhou, C.Y. Zhou, Y. Tian, "Review on thermal energy storage with phase change materials (PCMs) in building applications." Applied Energy 92 (2012), pp. 593-605. DOI:10.1016/j.apenergy.2011.08.025.

6. A.M. Khudhair, M.M., Farid, M.M. "A review on energy conservation in building applications with thermal storage by latent heat using phase change materials." Energy Conversion and Management 45 (2004), pp. 263-275. DOI:10.1016/S01968904(03)00131-6.

7. K.O. Lee, M.A. Medina, E. Raith, X. Sun, "Assessing the integration of a thin phase change material (PCM) layer in a residential building wall for heat transfer reduction and management." Applied Energy 137 (2015), pp. 699-706. DOI:10.1016/j.apenergy.2014.09.003.

8. M. Kenisarin, K. Mahkamov, „Passive thermal control in residential buildings using phase change materials." Renewable and Sustainable Energy Reviews 55 (2016), pp. 371-398. DOI:10.1016/j.rser.2015.10.128

9. V.V. Tyagi, S.C. Kaushik, S.K., T. Akiyama, "Development of phase change materials based microencapsulated technology for buildings: A review." Renewable and Sustainable Energy Reviews 15 (2011), pp. 1373-1391. DOI:10.1016/j.rser.2010.10.006.

10. R.K. Sharma, P. Ganesan, V.V. Tyagi, H.S.C. Metselaar, S.C. Sandaran. "Developments in organic solid-liquid phase change materials and their applications in thermal energy storage." Energy Conversion and Management 95 (2015), pp. 193-228. DOI:10.1016/j.enconman.2015.01.084.

11. J. Skovajsa, M. Koláček, M. Zálesák. "Phase Change Material Based Accumulation Panels in Combination with Renewable Energy Sources and Thermoelectric Cooling", Energies 2017, 10, 152; doi:10.3390/en10020152.

12. S.A. Memon. "Phase change materials integrated in building walls: A state of the art review". Renewable and Sustainable Energy Reviews 31 (2014) 870-906. http://dx.doi.org/10.1016/j.rser.2013.12.042. 
13. Addendum to OIB Guideline 6, 2015: www.oib.or.at.

14. PureTemp. 2019.(http://www.puretemp.com/stories/puretemp-25-tds.

15. Department of Energy, Energy Plus https://energyplus.net/.

16. P.C. Tabares-Velasco, C. Christensen, M. Bianchi. "Verification and validation of EnergyPlus phase change material model for opaque wall assemblies." Building and Environment 54 (2012), pp. 186-196. DOI:10.1016/j.buildenv.2012.02.019.

17. A. Tardieu, S. Behzadu, J.J.J. Chen, M.M. Farid. "Computer Simulation and Experimental Measurements for an Experimental PCM-Impregnated Office Building". In Proceedings of Building Simulation 2011: 12th Conference of International Building Performance Simulation Association, Sydney, 14-16 November.

18. Austrian Standard B8110-3 Thermal protection in building construction - Part 3: Determination of the operating temperature in summer (Prevention of summerly overheating). ÖNORM B 8110-3: 20180901. 